\title{
Repair of Tracheoesophageal Fistula under Laryngeal Microsurgery Approach: Case Report and Literature Review
}

\author{
Mun Soo Han (D), Gunhwee Yum (D), Kyung Ho Oh (D), and Soon Young Kwon iD \\ Department of Otorhinolaryngology-Head and Neck Surgery, Korea University Ansan Hospital, Korea University College of Medicine,
} Ansan, Korea

기관식도 누공에 대한 후두미세수술 접근하 재건술: 증례 보고 및 문헌 검토

한문수, 염건휘, 오경호, 권순영

고려대학교 의과대학 안산병원 이비인후-두경부외과학교실

Patients with tracheoesophageal fistula show signs of aspiration, possibly leading to pneumonia, which could be fatal to bed-ridden patients. Tracheoesophageal fistula occurs as a complication of intubation, tracheostomy tube insertion and nasogastric tube insertion. Possible etiology is pressure and ischemic necrosis given by tracheostomy tube and nasogastric tube to trachea and esophagus; or in some cases, larynx and hypopharynx. Meanwhile, for repair of tracheoesophageal fistula, transcervical approach can be considered but takes relatively long operation time and is not appropriate for patients with underlying diseases. We report a case of tracheoesophageal fistula complicated several years after tracheostomy tube and nasogastric tube insertion who came to medical attention with signs of aspiration. Authors successfully performed repair of the fistula under laryngeal microsurgery approach without skin incision and dissection, and thereby report the experience with review of literature.

Keywords Tracheoesophageal fistula; Aspiration pneumonia; Tracheostomy;

Gastrointestinal intubation; Microsurgery.

\section{서 론}

기도는 후두에 의해 인두 및 식도에서의 연하운동 시 음식물이 유입되지 않도록 보호 된다. 흡인(aspiration)은 연하기능에 장애가 있거나 후두가 하부 기도를 보호하지 못하 여 음식물이 하기도로 유입되는 현상이다. 이는 기능적인 장애에 의해서도 발생할 수 있 지만 해부학적 이상에 의해서도 발생할 수 있다. 구조적인 이상은 선천성 기형에 의해 나타날 수 있으며, 후천적 원인으로는 악성 종양, 경부 수술, 외상 등에 의해서 발생할 수 있다. ${ }^{1,2)}$ 그 중 기관절개술의 합병증으로서의 기관식도 누공(tracheoesophageal fistula)은 그 발생율이 $1 \%$ 미만이나, 임상 양상으로서 흡인성 폐렴을 일으킬 수 있고, 장 기간 기관절개공을 유지하는 환자들은 일반적으로 전신 상태가 양호하지 않고 와상 상
Received July 20, 2020

Revised August 19, 2020

Accepted September 16, 2020

Corresponding Author Soon Young Kwon, MD, PhD Department of OtorhinolaryngologyHead and Neck Surgery, Korea University Ansan Hospital, Korea University College of Medicine, 123 Jeokgeum-ro, Danwon-gu, Ansan 15355, Korea

Tel $+82-31-412-5170$

Fax +82-31-412-5174

E-mail entkwon@korea.ac.kr

\section{ORCID iDs}

Mun Soo Han (D)

https://orcid.org/0000-0003-1359-6248

Gunhwee Yum (D)

https://orcid.org/0000-0002-6143-5978 Kyung Ho Oh (1)

https://orcid.org/0000-0003-2075-5905

Soon Young Kwon (D)

https://orcid.org/0000-0002-1501-390X

This is an Open Access article distributed under the terms of the Creative Commons Attribution Non-Commercial License (https://creativecommons.org/ licenses/by-nc/4.0) which permits unrestricted non-commercial use, distribution, and reproduction in any medium, provided the original work is properly cited. 
태로 지내는 경우도 많아, 기관식도 누공에 의한 흡인성 폐렴 이 치명적인 합병증으로 이어질 수 있다. ${ }^{3)}$ 한편, 후두기관식도 열(laryngotracheoesophageal cleft)은 그 범위에 따라서 치 료 방법이 결정되며, 범위가 성문 주변에 국한된 경우 내시경 적 접근(endoscopic approach)하 재건술을 우선 고려하고, 하방으로 윤상연골을 넘는 경우엔 경부접근법(transcervical approach) 등의 술식이 필요하다. ${ }^{4)}$ 본 저자들은 흡인을 주소 로 내원하여 발견된 기관식도 누공에 대하여 후두미세수술 적 접근을 통해 재건술을 성공적으로 시행한 증례를 경험하 여 이를 문헌 검토와 함께 보고하는 바이다.

\section{증 례}

69세 남자 환자가 내원 1주전부터 발생한 흡인을 주소로 본원 이비인후과 외래로 내원하였다. 이전 병력으로서 2016년 교통사고에 의하여 경막하 출혈이 발생하여 본원 신경외과 및 중환자실 입원 치료를 받았으며 당시 신경외과 의사에 의하 여 기관절개술을 시행받은 바 있었다. 그 전의 내과적 병력으 로 고혈압이 있었으며 30 갑년 흡연력, 매일 소주 1 병의 음주 력이 있었다. 환자는 당시의 뇌출혈 이후 반혼수 의식 상태 및 와상 상태로 지내왔으며 1차례 흡인성 폐렴으로 입원하여 치료를 받았었다. 이비인후과 내원 당시 보호자의 진술에 따 르면, 내원 1 주일 전부터 기침할 때 기관절개관(trahcheostomy tube)을 통하여 다량의 물이 가래와 섞여 나온다고 하 였다. 환자는 장기간 비위관(nasogastric tube)으로 영양 공급 을 받고 있는 상태였으며 풍선이 없는(uncuffed) 기관절개관 이 삽입되어 있었다.

기관절개관을 제거 후 기관창(tracheostoma)을 통해 $70^{\circ}$ 후
두경으로 하부 기도를 확인하였을 때 기관 내 해부학적 이상 소견은 관찰되지 않았으나, 기관창보다 상부를 관찰하자 성 문하 후두의 후방부에서 누공이 확인되었다(Fig. 1A). 비강을 통해 굴곡 후두경(fiberoptic laryngoscope)으로 관찰할 땐 양측 성대마비로 인한 중앙 고정 상태가 보였지만 후두 및 성 대 후방부는 노출이 되지 않아 누공을 확인할 수 없었다. 흡 인을 막기 위해 우선 금식하도록 하였고, 이후 시행한 경부 컴 퓨터단층촬영검사(CT)에선 양측 피열 연골(arytenoid cartilage) 사이에 약 $3 \mathrm{~mm}$ 크기의 누공이 확인되었다(Fig. 1B). CT 촬영 2일 후 외래로 재내원하였을 때 위 내용물(gastric content)이 하기도로 흡인되는 것을 막기 위하여 풍선이 있는 (cuffed) 기관절개관으로 교체하였으나, 이후 비위관 영양 공 급을 재개하자 위 내용물의 흡인 및 기관창 주변으로의 누출, 발열 동반한 폐렴 발생하여 응급실 통해 내원해 본원 감염내 과에 입원하였다.

저자들은 환자가 뇌출혈의 기저질환력이 있고 와상 상태이 며, 풍선이 있는 기관절개관을 삽관해도 비위관으로 공급된 위 내용물이 쉽게 흡인되는 것에 대해, 후두경과 컴퓨터단층촬 영검사에서 확인된 기관식도 누공을 통해 성문하 기도까지 흡인이 발생하였다고 판단하였다. 또한 근본적으로 누공을 폐쇄하지 않을 경우 반복적으로 흡인성 폐렴이 발생할 것으 로 예상되었다. 이에 보호자와 상의 후 기관식도 누공에 대한 수술적 폐쇄를 진행하기로 하였다.

수술적 치료 접근 방법으로는 피부절개 없는 후두미세수 술 접근법과 경부접근법을 고려하였다. 후자의 경우, 갑상연골 의 후방을 박리하여 하인두로 접근하여 누공을 봉합하거나 후두기관분리술 혹은 협영역 후두전절제술 등을 고려하였다. 하지만, 환자가 고령이고 뇌출혈 이후 와상 상태로서 전신 상

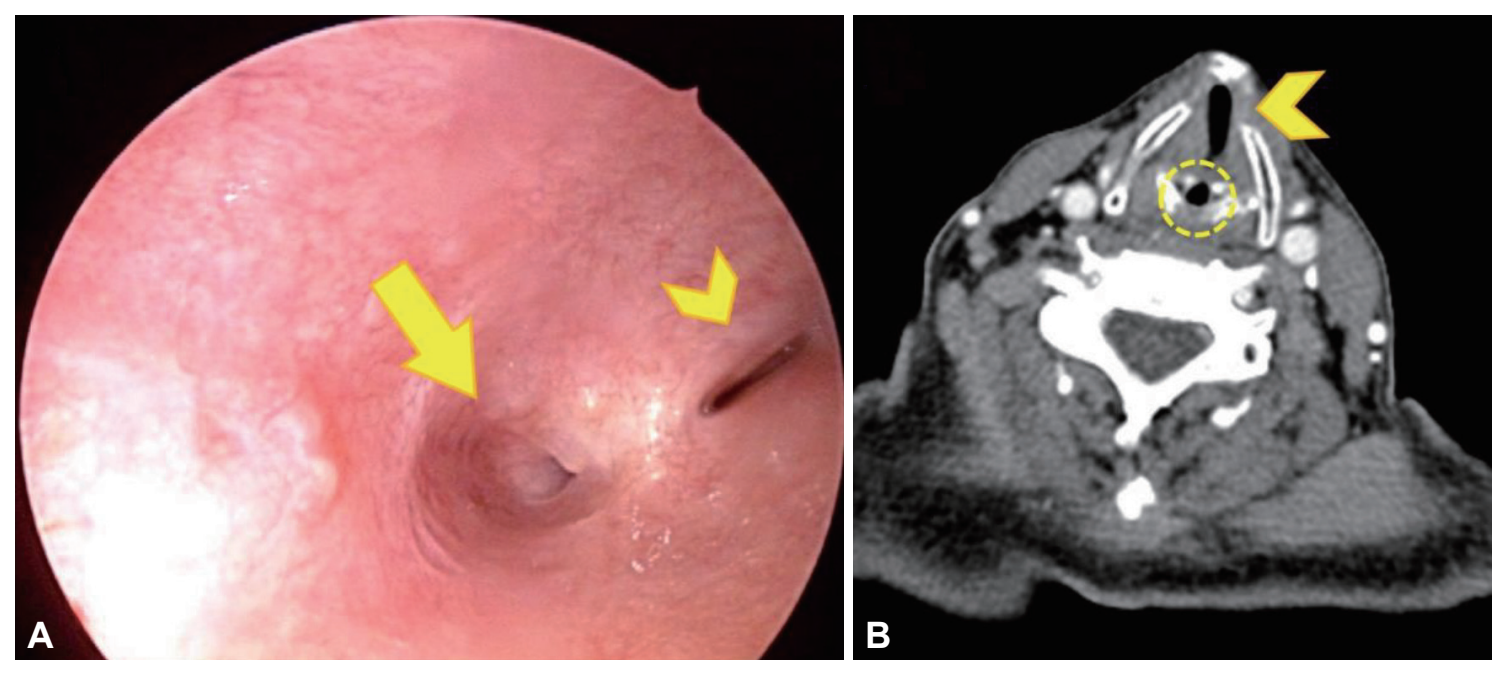

Fig. 1. Preoperative findings of tracheoesophageal fistula. A: Laryngoscopy finding of tracheoesophageal fistula (arrow) at the posterior portion of glottis (arrowhead), examined through tracheostoma after tracheostomy tube removal for examination. B: CT finding of $3 \mathrm{~mm}$-sized air-density tracheoesophageal fistula (dotted circle) located between both arytenoid cartilages behind glottis (arrowhead). 

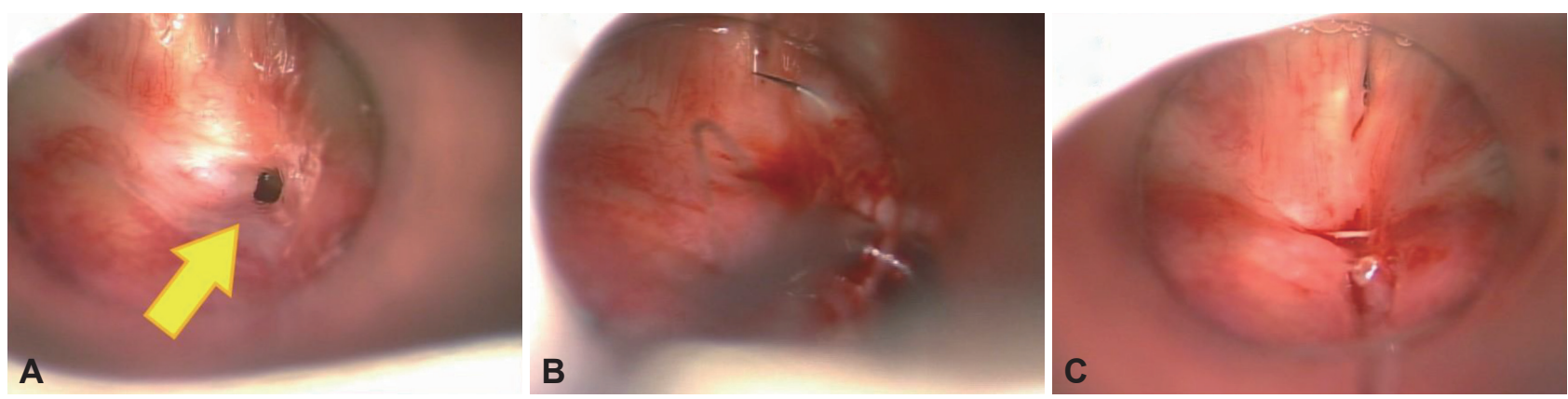

Fig. 2. Laryngeal microsurgery findings. A: After general anesthesia, suspension laryngoscope was inserted and the fistula (arrow) was observed between arytenoid cartilages, posterior to glottis. B: Epithelium of the $3 \mathrm{~mm}$-sized fistula lumen was removed with micro laryngeal cup forceps and microscissors, then closed with Vicryl 5-0 suture. C: The fistula is sutured and closed.

태가 양호하지 않은 점을 고려하였을 때 수술 시간이 보다 짧 게 걸리면서 덜 침습적인 후두미세수술 접근법을 우선 시도 하기로 결정하였다.

전신마취하에 현수후두경을 통해 성대 후방부를 노출시 켰고, 수술현미경으로 관찰 시 양측 피열연골 사이의 누공을 확인할 수 있었다(Fig. 2A). 누공은 직경 약 $3 \mathrm{~mm}$ 정도의 크 기였으며 주변부로 섬유화가 되어 있어 흥터 변형이 된 상태가 의심되었다. Micro laryngeal cup forceps 및 미세가위(microscissors)로 누공의 상피를 제거하였다. 이후 누공 주변부 를 5-0바이크릴(Vicryl, Ethicon, NJ, USA) 봉합사로 봉합하 여 누공을 폐쇄하였다(Fig. 2B and C).

수술 2개월 후 기관창을 통해 상부의 성문부 후방을 확인 하였을 때 성문 후방의 기관식도 누공이 폐쇄되었음을 확인 하였으며(Fig. 3), 수술 전 있었던 흡인 증상 또한 호전되어 기 존의 기관창을 풍선이 없는 관으로 변경하였고, 안정적인 상 태로 추적 관찰 중이다.

\section{고 찰}

기관식도 누공은 후천적으로 발생하여 기관과 식도에 교통 이 있는 경우를 말하는데, 그 원인으로는 주로 기관 삽관, 악 성 종양 등이 있다.1) 이와 달리 후두기관식도열은 주로 선천 성 기형으로 발생하는 경우에 쓰이는 명칭으로서, 주로 소아 에서 발견되지만 성인이 되어서 증상이 생기거나 다른 질환의 치료 중 후두기관식도열이 우연히 발견된 증례들도 보고되었 다. ${ }^{5,6)}$ 본 증례의 환자에서는 후천적 원인에 의해 발생한 것으 로 생각되는 기관식도 누공에 대해 선천성 원인에 의한 후두 기관식도열의 치료 방침을 응용하여 수술을 시행하였는데, 즉 성문부에 국한된 누공을 최소 침습 술식으로서 후두미세수 술 접근법으로 폐쇄한 것이다.

본 증례의 경우 누공이 성문부 후두와 하인두 사이에 위치 하였기 때문에 기관식도 누공이라는 명칭보다는 후두기관식

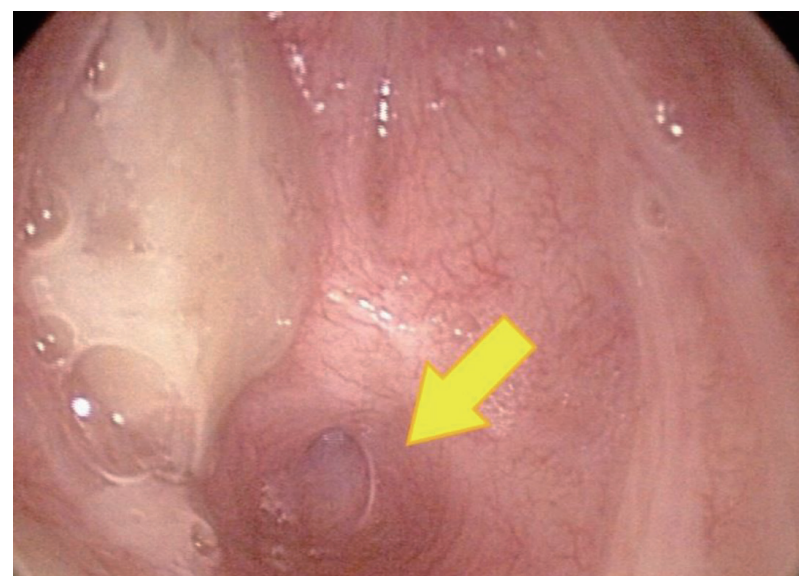

Fig. 3. Laryngoscopy finding after 2 months from surgery. The repaired fistula (arrow) is healed and closed.

도열이 해부학적으로 옳은 표현이다. 그러나 기존 문헌을 보 면 1950년대 이후, 후천적으로 발생하는 기관식도 누공의 발 생 기전으로서 풍선이 있는 기관절개관과 비위관이 주요 원인 으로 지목되어 여러 연구 보고가 있었고, 발생 기전으로는 이 러한 삽관된 기관절개관과 비위관이 기관과 식도벽에 압력 (pressure)과 허혈성 괴사(ischemic necrosis), 미란(erosion) 을 유발하는 것으로 기술되었다.3,7) 본 증례에서도 뇌출혈 후 와상 상태로 지내며 기관절개관과 비위관을 장기간 유지한 환자에서 해당 부위에 지속적인 압력과 허혈이 유발되어 누 공의 발생을 초래했을 것으로 생각되었고, 그래서 누공의 실 제 해부학적 위치는 후두에 위치하나, 기존 문헌에서 다루고 있는 장기간 기관절개관 및 비위관 유지 환자에서 발생한 후 천적 원인의 누공인 점을 고려하여 기관식도 누공으로 기술 하였다. 또한, 기관절개관의 풍선이 있는 기관이 아닌 그보다 상부인 성문부에서 누공이 발생한 것으로 보아 기관절개관 풍선보다는 하인두와 식도를 통해 삽입된 비위관이 기관식 도 누공의 원인으로 생각되었다.

내시경적 소견을 살펴보면, 후두기관식도열은 발생학적으 로 배아기(embryonic period)에 피열간근(interarytenoid 
muscle)과 윤상연골이 불완전 형성되어 발생하는 것으로 알 려져 있으며, 후두경 검진 시 탐침(probe)으로 피열간 홈(interarytenoid groove)의 깊이를 확인하여 후두열의 존재 여 부를 확인할 수 있다. ${ }^{4}$ 후두기관식도열의 범위가 더 큰 경우 엔 윤상연골이 탐침으로 촉진되지 않을 수도 있으며, 이 때엔 후두를 넘어 기관까지 포함돼 있음을 알 수 있다. 기관식도 누공에선 발생 원인에 따라 비위관 또는 기관절개관의 풍선 이 위치해 있던 위치에 점막 등 정상 조직의 소실 및 기관을 통해서 식도의 비위관이 보이는 등의 내시경 소견을 확인할 수 있다. ${ }^{3)}$

수술적 치료 시 접근 방법에 대해 살펴보면, 기존 문헌에서 는 기관식도 누공에 대한 수술적 치료로서 피부절개 후 경 부접근법 등 보다 침습적인 치료가 주로 기술되어 있다. ${ }^{3,8)}$ 그 러나 기관식도 누공이 발생하는 환자들은 주로 와상 상태로 오래 지내는 환자들로서, 전신마취 및 경부접근법 수술을 받 기에 위험도가 높은 경우가 많으며, 본 증례의 환자도 이에 해 당하였다.

한편, 선천성 후두기관식도열에 대한 수술적 치료 시 그 접 근 방법은 환자의 전신 상태, 증상 여부 및 중증도 등에 따라 달라지나 제일 중요한 것은 후두 결손 부위의 범위이다. ${ }^{4)}$ 흡인 등의 증상이 심각하지 않고 후두 결손 부위가 성문에 국한되 어 있는 Benjamin and Inglis classification type I의 경우엔 수술적 치료 이전에 합병증을 막는 대증적 치료를 시도해볼 수 있다. 식이의 점도를 높이고 바륨 삼킴 검사 결과에 따라 금식 시간을 설정하고, 제산제를 복용하는 등이 이에 해당한 다. 이런 비수술적 치료를 시행할 수 없거나, 그런 치료에 실패 하였거나, 결손 부위가 성문하부까지 포함된 type II 환자들 의 경우는 수술적 치료 중에서 내시경적 접근을 고려할 수 있 다. 내시경적 수술은 비교적 합병증이 적으면서 성공률도 높 은 장점이 있으며, 그 술식은 마취 후 현수 후두경(suspension laryngoscope)을 삽입한 뒤, 후두열의 양측 점막을 $\mathrm{CO}_{2}$ 레이저를 조사하여 벗긴 뒤, 내시경 기구(endoscopic instruments)를 이용해 흡수성 봉합사로 봉합한다. 결손 부위가 윤 상연골을 넘어서 경부 또는 흉부 기관까지 이어져 있는 경우 엔 피부 절개 및 경부접근법을 통한 재건술을 고려한다. ${ }^{4)}$

저자들은 본 증례에서 그 발생 기전은 후천적 기관식도 누 공과 같이 비위관이 원인이었으나, 환자의 기저질환, 고령, 성 문부에 $3 \mathrm{~mm}$ 크기로 국한된 누공인 점을 고려해 선천성 후 두기관식도열의 치료 방법과 같이 내시경적 접근 등 비침습적 접근 방법을 우선 고려하였다. 이는 외부 접근법보다 수술 시
간이 길지 않으며 피부절개 및 경부조직박리를 하지 않기 때 문에 수술 후 부작용이 비교적 적은 것으로 알려져 있고, 그 성공율도 80 100\%까지 보고되고 있다. ${ }^{9}$ 본 증례에서도 후 두미세수술 접근하 재건술 후 급성 합병증 없이 누공이 폐쇄 된 상태로, 수술 후 환자의 증상도 흡인 없이 안정적이다.

이에 저자들은 기관절개술 후 장기간 기관절개관, 비위관 을 삽입한 뒤에 후천적으로 발생한 기관식도 누공에 대해서 후두미세수술 접근을 통해 성공적으로 폐쇄술을 시행한 증 례를 문헌 검토와 함께 보고한다.

중심 단어: 기관식도 누공, 흡인성 폐렴, 기관절개술, 위장관 삽관, 미세수술.

Acknowledgments

None.

Conflicts of Interest

The authors have no financial conflicts of interest.

Authors' Contribution

Conceptualization: Mun Soo Han, Kyung Ho Oh, Soon Young Kwon. Investigation: Mun Soo Han, Gunhwee Yum, Soon Young Kwon. Supervision: Kyung Ho Oh, Soon Young Kwon. Writing-original draft: Mun Soo Han, Gunhwee Yum, Soon Young Kwon. Writingreview \& editing: Kyung Ho Oh, Soon Young Kwon. Approval of final manuscript: all authors.

\section{REFERENCES}

1. Couraud L, Ballester MJ, Delaisement C. Acquired tracheoesophageal fistula and its management. Semin Thorac Cardiovasc Surg 1996; 8(4):392-9.

2. Leboulanger N, Garabedian EN. Laryngo-tracheo-oesophageal clefts. Orphanet J Rare Dis 2011;6:81.

3. Paraschiv M. Tracheoesophageal fistula--a complication of prolonged tracheal intubation. J Med Life 2014;7(4):516-21.

4. Johnston DR, Watters K, Ferrari LR, Rahbar R. Laryngeal cleft: evaluation and management. Int J Pediatr Otorhinolaryngol 2014;78(6): 905-11.

5. Shimizu K, Uno A, Takemura K, Ashida N, Oya R, Kitamura T, et al. A case of adult congenital laryngeal cleft asymptomatic until hypopharynx cancer treatment. Auris Nasus Larynx 2018;45(3):640-3.

6. Thornton M, Rowley H, Conlon BJ, Russell JD. Type I laryngeal cleft: late presentation. J Laryngol Otol 2001;115(10):821-2.

7. Thomas AN. The diagnosis and treatment of tracheoesophageal fistula caused by cuffed tracheal tubes. J Thorac Cardiovasc Surg 1973; 65(4):612-9.

8. Muniappan A, Wain JC, Wright CD, Donahue DM, Gaissert H, Lanuti $M$, et al. Surgical treatment of nonmalignant tracheoesophageal fistula: a thirty-five year experience. Ann Thorac Surg 2013;95(4): 1141-6.

9. Pezzettigotta SM, Leboulanger N, Roger G, Denoyelle F, Garabedian EN. Laryngeal cleft. Otolaryngol Clin North Am 2008;41(5):913-33. 